\title{
REDUCCION DE LA CARGA MICROBIANA Y ELIMINACION DE MICROORGANISMOS PATOGENOS EN ALIMENTOS BALANCEADOS PARA POLLOS POR RADIACION GAMMA.
}

\author{
JOHNNY VARGAS RODRIGUEZ \\ ROGELIO MELGAR PEREZ \\ PAULA HUAMAN LAZO SANTA CRUZ
}

Laboratorio de Microbiología y Fisicoquímico, Proyecto de Irradiación Multiuso, Instituto Peruano de Energía Nuclear.

\author{
RESUMEN
}

\begin{abstract}
Este artículo reporta el estudio acerca de la radiación del alimento balanceado para pollos.Estudios microbiológicos demostraron que la dosis de irradiación de ${ }^{5} \mathrm{kGy}$ parece ser la adecuada para reducir el número de microorganismos aerobicos y la eliminación de organismos patógenos.El valor nutritivo del alimento no fue afectado significativamente por el tratamiento de radiación.
\end{abstract}

PALABRAS CLAVES: Radiación, Alimento balanceado, pollos.

\section{SUMMARY}

This article reports the study about the irradiation of mixed chicken feed.Microbiological studies showed that the irradiation dose of $5 \mathrm{kGy}$ seem to be suitable for reducing the number of aerobic microorganisms and the elimination of pathogenic organisms. The nutritive value of the feed was
not significantly affected by radiation treatment.

KEY WORDS: Radiation, Mixed feed, chicken.

\section{INTRODUCCION}

La industria de alimentos balanceados en el Perú se encuentra en una fase creciente como consecuencia de un mayor consumo de carne de pollo. La elaboración de alimentos balanceados es uno de los factores primordiales en la producción de carne de pollo (Cuellar, 1974), debido a que constituye entre el $70 \%$ al $75 \%$ del costo total de producción. De aquí que cualquier mejora o deterioro en la calidad de los alimentos tiene gran influencia en la productividad, aumentándola o disminuyéndola (Bueno, 1980).

La mezcla de ingredientes alimenticios y alimentos balanceados son a menudo transportadores de Salmonella y otros organismos enteropatógenicos. Por lo tanto existe una gran necesidad para la descontaminación de alimentos. La descontaminación por métodos térmicos o mediante ácidos antimicrobiales llevarán a una considerable reducción de los patógenos entericos, pero sin su adecuada eliminación (Mossel, 1979).

Dada la implicancia de este problema, es importante emplear tecnologías que contribuyan a la eliminación de estos microorganismos patógenos. La tecnología de radiación gamma ofrece una alternativa de solución, como se muestra en el presente trabajo que tiene por finalidad mejorar la calidad higiénica de los alimentos balanceados para pollos y reemplazar el uso de aditivos químicos y fumigantes.

\section{MATERIALES Y METODOS}

\section{OBTENCION DE LA MUESTRA}

El material de investigación (alimento balanceado no peletizado para pollos) fue obtenido de la Planta de Alimentos de la Universidad Nacional Agraria La Molina y de algunos mercados de Lima.El muestreo fue realizado en forma aleatoria, tomándose $1 \mathrm{~K}$ de muestra por cada $50 \mathrm{~K}$.

\section{PREPARACION DE LA MUESTRA}

El alimento se envasó en bolsas de polietileno de alta densidad, previamente esterilizadas por radiación gamma, las cuales fueron hermeticamente selladas, conteniendo cada una $25 \mathrm{~g}$ de muestra.

Para determinar la tasa de dosis $(\mathrm{kGy} / \mathrm{h})$ que debe recibir $1 \mathrm{~K}$ de alimento dentro del cilindro de radiación. se realizó la dosimetría química por el método de Fricke.

$$
\begin{aligned}
1 \mathrm{kGy} & =1000 \mathrm{~Gy} \\
1 \mathrm{~Gy} & =1 \mathrm{Joule} / \mathrm{K} .
\end{aligned}
$$

Las muestras fueron colocadas en el equipo de radiación Gammacell 220 con fuente de Cobalto-60 para ser irradiadas a tres diferentes dosis ( 1,3 y $5 \mathrm{kGy})$.Una muestra sin irradiar $(0 \mathrm{kGy})$ fue utilizada para fines comparativos.Posteriormente, se realizaron los análisis fisicoquímicos y microbiológicos de acuerdo a métodos establecidos. 


\section{RESULTADOS}

\section{1.- ANALISIS FISICOQUIMICO}

Tabla 1. Intercomparación del Análisis proximal en alimento balanceado para pollos irradiado y no irradiado.

\begin{tabular}{|llrr|}
\hline \multicolumn{1}{|c|}{ Control } & & $5 \mathrm{kGy}$ \\
\hline$\%$ & Humedad & 11,0 & 11,0 \\
$\%$ & Proteinas & 20,0 & 21,0 \\
$\%$ & Grasa & 3,4 & 3,0 \\
$\%$ & Fibra Cruda & 3,0 & 3,2 \\
$\%$ & Ceniza & 8,0 & 7,5 \\
$\%$ & Carbohidratos & 54,6 & 54,3 \\
\hline
\end{tabular}

\section{2.- ANALISIS MICROBIOLOGICO}

Tabla 2. Límite Microbiano en Diferentes Muestras de Alimento Balanceado para pollos.

\begin{tabular}{|lccc|}
\hline & Muestra A & Muestra B & Muestra C \\
\hline Recuento de microorganismos & $9,6 \times 10^{5}$ & $8,2 \times 10^{5}$ & $6,3 \times 10^{5}$ \\
aerobios mesófilos (ufc/g) & & & $6,0 \times 10^{4}$ \\
Recuento de mohos (ufc/g) & $3,7 \times 10^{4}$ & $4,8 \times 10^{4}$ & $2,0 \times 10^{4}$ \\
Recuento de levaduras (ufc/g) & $2,7 \times 10^{4}$ & $3,3 \times 10^{4}$ & $3,7 \times 10^{4}$ \\
Recuento de enterobacterias & $1,7 \times 10^{4}$ & $7,7 \times 10^{4}$ & $>1100$ \\
Coliformes totales (NMP/g) & $>1100$ & $>1100$ & $>1100$ \\
Coliformes fecales (NMP/g) & $>1100$ & $>1100$ & Ausente \\
Detección de Salmonella $(25 \mathrm{~g})$ & Ausente & Ausente & \\
\hline
\end{tabular}

Tabla 3. Intercomparación de la población microbiana en Alimento Balanceado recien procesado en polvo y en pellets.

\begin{tabular}{|lrc|}
\hline & $\begin{array}{r}\text { A. Balanceado } \\
\text { en polvo. }\end{array}$ & $\begin{array}{r}\text { A. Balanceado } \\
\text { pellets. }\end{array}$ \\
\hline Recuento de microorganismos & $1,1 \times 10^{4}$ & $2,4 \times 10^{3}$ \\
aerobios mesófilos (ufc/g) & $1,4 \times 10^{4}$ & $1,2 \times 10^{2}$ \\
Recuento de mohos (ufc/g) & $2,0 \times 10^{4}$ & $6,4 \times 10^{2}$ \\
Recuento de levaduras (ufc/g) & $>1100$ & $<3$ \\
Coliformes totales (NMP/g) & 90 & $<3$ \\
Coliformes fecales (NMP/g) & $<3$ & $<3$ \\
E. coli (NMP/g) & Ausente & Ausente \\
Detección de Salmonella (25g) & &
\end{tabular}


Tabla 4. Efecto de las dosis de radiación gamma sobre la población microbiana en alimento balanceado en polvo.

\begin{tabular}{|lrrrrr|}
\hline & Control & $1 \mathrm{kGy}$ & $3 \mathrm{kGy}$ & $5 \mathrm{kGy}$ \\
\hline $\begin{array}{lrrrr}\text { Recuento de microorganismos } \\
\text { aerobios mesófilos (ufc/g) }\end{array}$ & $6,3 \times 10^{5}$ & $5,5 \times 10^{4}$ & $6,5 \times 10^{2}$ & $4,3 \times 10^{2}$ \\
Recuento de mohos (ufc/g) & $4,8 \times 10^{4}$ & $6,1 \times 10^{3}$ & 30 & 10 \\
Recuento de enterobacterias & $3,7 \times 10^{4}$ & $1,1 \times 10^{4}$ & $3,4 \times 10^{2}$ & $<10$ \\
Coliformes totales (NMP/g) & $>1100$ & $>1100$ & 4 & $<3$ \\
Coliformes fecales (NMP/g) & $>1100$ & $>1100$ & 500 & $<3$ \\
Detección de Salmonella (25g) & Ausente & Ausente & Ausente & Ausente \\
\hline
\end{tabular}

Tabla 5. Contenido de microorganismos en alimento balanceado para pollos.

\begin{tabular}{|c|c|c|c|c|c|c|}
\hline \multirow[b]{3}{*}{ Clase de Alimento } & \multicolumn{6}{|c|}{ Contenido de microorganismos } \\
\hline & \multicolumn{2}{|l|}{ 1. Normal } & \multicolumn{2}{|l|}{ 2. Elevado } & \multicolumn{2}{|c|}{ 3. Muy elevado } \\
\hline & $\begin{array}{l}\text { Bacterias } \\
\text { Mill/g }\end{array}$ & $\begin{array}{l}\text { Hongos } \\
1000 / g\end{array}$ & $\begin{array}{l}\text { Bacterias } \\
\text { Mill/g }\end{array}$ & $\begin{array}{l}\text { Hongos } \\
1000 / g\end{array}$ & $\begin{array}{l}\text { Bacteric } \\
\text { Mill/g }\end{array}$ & $\begin{array}{l}\text { Hongos } \\
1000 / g\end{array}$ \\
\hline $\begin{array}{l}\text { Harina de sangre } \\
\text { Harina de huesos }\end{array}$ & $<1$ & $<10$ & $1-4$ & $10-40$ & $>4$ & $>40$ \\
\hline Harina de pescado & $<2$ & $<20$ & $2-5$ & $20-50$ & $>5$ & $>50$ \\
\hline $\begin{array}{l}\text { Cereales (excepto maiz) } \\
\text { grano,afrecho,grano trit. }\end{array}$ & $<6$ & $<80$ & $6-10$ & $80-200$ & $>10$ & $>200$ \\
\hline Granos de maiz & $<4$ & $<50$ & $4-8$ & $50-100$ & $>8$ & $>100$ \\
\hline $\begin{array}{l}\text { Subproductos de molineria } \\
\text { Harina de bulbos de forraje } \\
\text { de reproceso }\end{array}$ & $<3$ & $<40$ & $3-6$ & $40-80$ & $>6$ & $>80$ \\
\hline $\begin{array}{l}\text { Extracto de grano triturado } \\
\text { de soya }\end{array}$ & $<1$ & $<20$ & $1-4$ & $20-80$ & $>4$ & $>80$ \\
\hline $\begin{array}{l}\text { Otros residuos de } \\
\text { obtencion de soya }\end{array}$ & $<2$ & $<50$ & $2-4$ & $50-100$ & $>4$ & $>100$ \\
\hline
\end{tabular}

FUENTE: Estacion Agricola Experimental y de Investigacion de Kiel, Republica Federal de Alemania. 
Fig. 1 REDUCCION DE AEROBIOS MESOFILOS POR RADIACION GAMMA

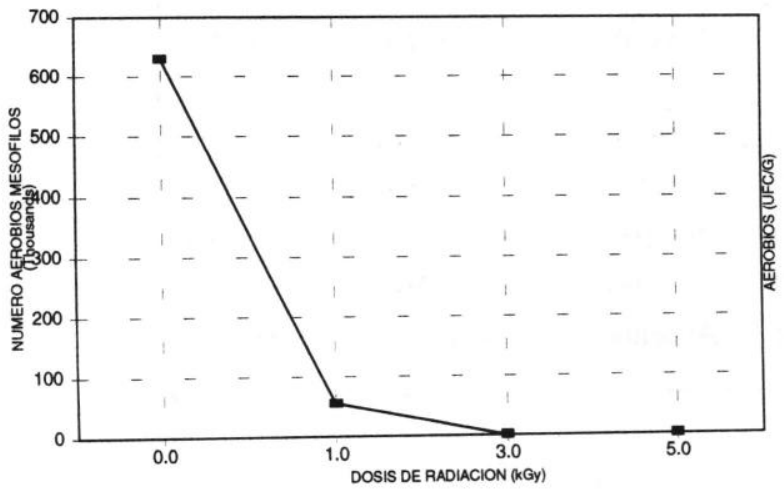

Fig. 3 REDUCCION DE COLIFORMES TOTALES

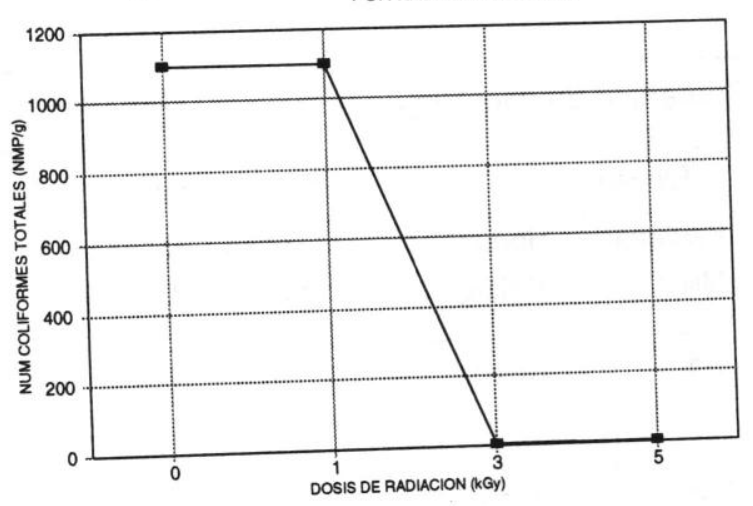

Fig. 2 REDUCCION DE ENTEROBACTERIAS POR RADIACION GAMMA

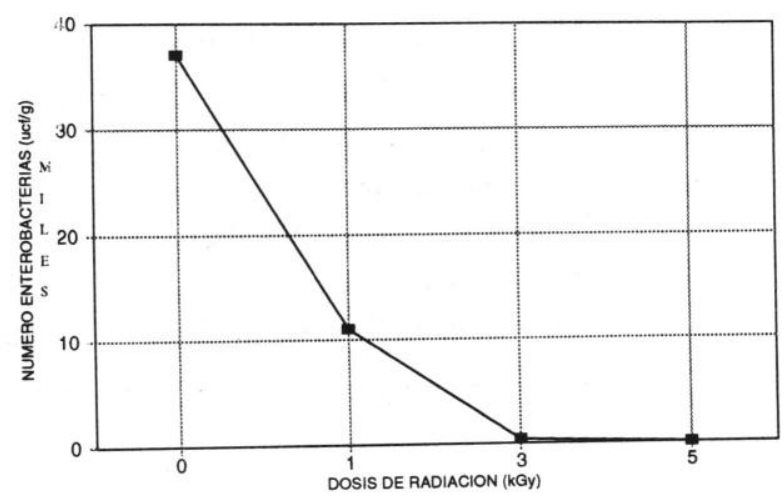

Fig. 4 REDUCCION DE COLIFORMES FECALES POR RADIACION GAMMA

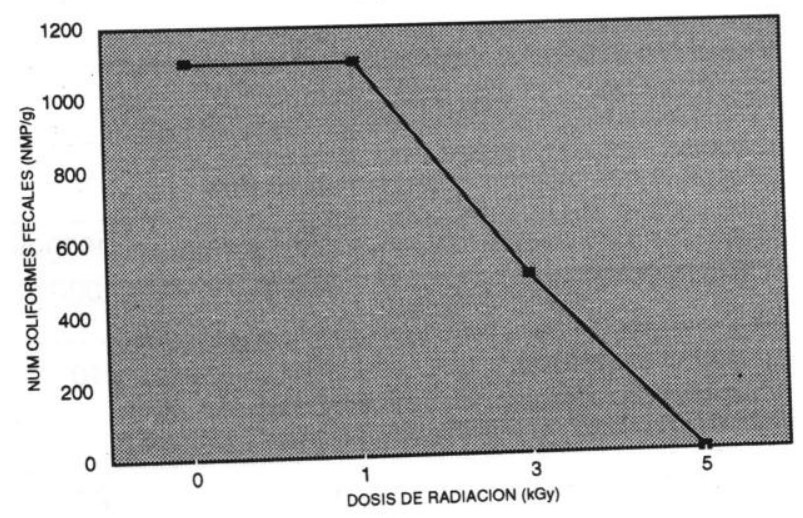

Fig. 5 REDUCCION DE HONGOS

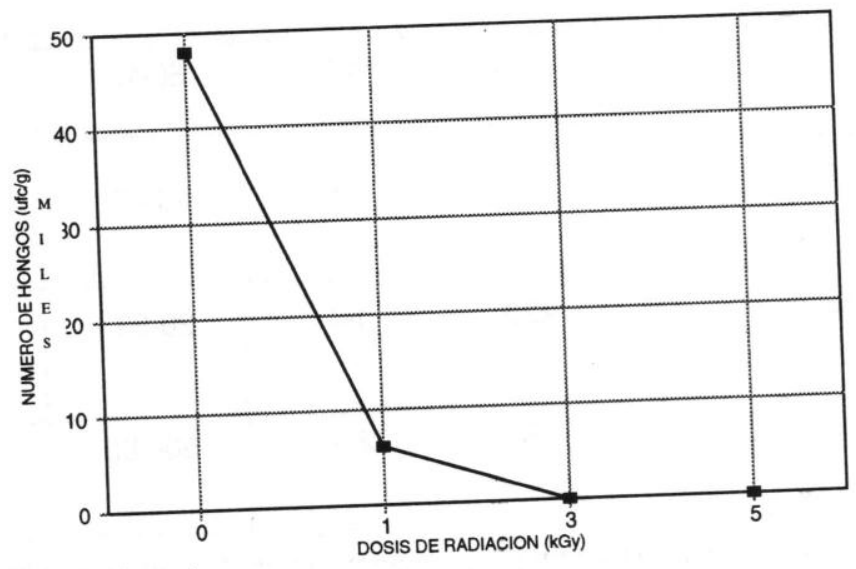




\section{DISCUSION}

Como se puede apreciar en la tabla 1, en el análisis proximal no se encontro diferencias significativas en el alimento balanceado no irradiado e irradiado a una dosis de $5 \mathrm{kGy}$.

Aunque no se han establecido los límites del contenido de microorganismos en el alimento balanceado para pollos;sin embargo, la Estación Agrícola Experimental y de Investigación de Kiel, República Federal de Alemania, determinó el número de colonias de hongos y bacterias en los diferentes ingredientes de los alimentos balanceados para pollos y los clasifica en tres niveles como se aprecia en la tabla 5 .Haciendo contraste entre nuestros resultados y la mencionada tabla podemos señalar:

1.- En la tabla 4, podemos notar claramente que las muestras analizadas presentan un recuento total de microorganismos aerobios mesófilos promedio igual a 6,8 x $10^{5} \mathrm{ufc} / \mathrm{g}$; esto significa que el alimento tiene un contenido aceptable de bacterias aerobias mesófilas.Sin embargo, es necesario notar que los recuentos totales bajos no siempre son representativos de alimentos higiénicos.

2.- Los coliformes son considerados como buenos indicadores de la calidad higiénica de los alimentos.Según los análisis microbiológicos realizados podemos señalar que el alimento balanceado para pollos presenta un número más probable de coliformes excesivamente elevado (> $1100 \mathrm{NMP} / \mathrm{g})$.

3.- Se encontró niveles de población de mohos de $4,8 \times 10^{4}$ ufc/g (tabla 4). Comparando con la tabla 5, podemos señalar que el alimento balanceado contiene una población elevada de hongos, con el riesgo de producción de toxinas perjudiciales para pollos.
4.- En la tabla 3, se puede apreciar que en el alimento peletizado que implica tratamiento térmico, la población de microorganismos aerobios mesófilos fué reducida en un ciclo logarítmico; los hongos son los más sensibles, por lo que se redujeron en dos ciclos logarítmicos; en cambio, los coliformes practicamente fueron eliminados.

El peletizado implica mayor costo y consumo de energía, y no se puede considerar completamente bactericida, ya que es factible una recontaminación bacteriana (North, 1993).

5.- En la tabla 4 y figs $1-5$ se puede apreciar que la dosis mínima óptima de $5 \mathrm{kGy}$ reduce adecuadamente la carga bacteriana y elimina microorganismos patógenos.

\section{AGRADECIMIENTOS}

Al Consejo Nacional de Ciencia y Tecnología (CONCYTEC) por la subvención económica otorgada para realizar el presente trabajo. A los Ingenieros Zootecnistas de la Planta de Alimentos de la Universidad Agraria La Molina por las facilidades y orientaciones brindadas.

\section{REFERENCIAS BIBLIOGRAFIAS}

BUENO, S. M. 1980.Efecto del ácido propiónico en diferentes niveles a raciones comerciales en la performance de pollos de carne.Tesis para adoptar el titulo de Ing. Zootecnista.Universidad Nacional Agraria La Molina. p7.

MOSSEL, A. 1979.Rationale for the use of ionizing radiation in the elimination of enteropathogenic bacteria from feeds.Decontamination of animal feeds by irradiation.STI/PUB/508. p6.

NORTH, M. O.; BELL, D. D. 1993. Manual de producción avícola. p679. 